\title{
Evaluation of Impermeable Covers for Bedding in Patients with Allergic Rhinitis
}

\author{
Ingrid Terreehorst, M.D., Eelko Hak, Ph.D., Albert J. Oosting, M.D., Ph.D., \\ Zana Tempels-Pavlica, M.D., Jan G.R. de Monchy, M.D., Ph.D., \\ Carla A.F.M. Bruijnzeel-Koomen, M.D., Ph.D., Rob C. Aalberse, Ph.D., \\ and Roy Gerth van Wijk, M.D., Ph.D.
}

\section{A B STRACT}

\section{BACKGROUN D}

Encasing bedding in impermeable covers reduces exposure to house-dust mites, but the clinical benefit of this intervention as part of mite-avoidance measures for patients with allergic rhinitis is not known. We performed a multicenter, randomized, placebocontrolled trial of one year of use of impermeable bedding covers in the bedrooms of patients with rhinitis who were sensitized to house-dust mites to determine the effects on the signs and symptoms of disease.

\section{METHODS}

Three participating university medical centers enrolled 279 patients with allergic rhinitis who were randomly assigned to receive impermeable or non-impermeable (control) covers for their mattress, pillow, and duvet or blanket. At the start of the study, all participants received information on general allergen-avoidance measures. The severity of rhinitis was measured on a rhinitis-specific visual-analogue scale and by means of a daily symptom score and nasal allergen provocation testing. We also measured the concentrations of Dermatophagoides pteronyssinus (Der p1) and D. farinae (Der f1) in dust from patients' mattresses, bedroom floors, and living-room floors at base line and after 12 months as a measure of the efficacy of the intervention.

RESULTS

A total of 232 patients completed the study. There was a significant reduction in Der p1 and Der $\mathrm{f} 1$ concentrations in the mattresses of the impermeable-cover group, whereas there was no significant reduction in the control group. However, there was no significant effect on the clinical outcome measures. Analyses of subgroups defined according to age, level of exposure, type and severity of sensitization, or characteristics of the patient's home had similar results.

CONCLUSIONS

Mite-proof bedding covers, as part of a structured allergy-control program, reduced the level of exposure to mite allergens. Despite the success of the intervention, this single avoidance measure did not lead to a significant improvement of clinical symptoms in patients with allergic rhinitis.
From the Department of Allergology, Erasmus Medical Center, Rotterdam (I.T., R.G.W.); the Department of Internal Medicine, Albert Schweitzer Hospital, Dordrecht (I.T.); the Julius Center for Health Sciences and Primary Care, University Medical Center Utrecht, Utrecht (E.H.); the Department of Dermatology, University Medical Center Utrecht, Utrecht (A.J.O., C.A.F.M.B.-K.); the Department of Allergology, University Hospital Groningen, Groningen (Z.T.-P., J.G.R.M.); and the Department of Immunopathology, Sanquin Research, Amsterdam (R.C.A.) - all in the Netherlands. Address reprint requests to $\mathrm{Dr}$. Gerth van Wijk at the Department of Allergology, Erasmus Medical Center, Dr. Molewaterplein 40, 3015 GD Rotterdam, the Netherlands, or at r.gerthvanwijk@erasmusmc.nl.

N EnglJ Med 2003;349:237-46. Copyright $@ 2003$ Massachusetts Medical Society. 
LLERGIC RHINITIS IS THE MOST PREValent of allergic diseases, affecting 20 million to 40 million people in the United States alone. Approximately $\$ 1.2$ billion is spent in the United States annually on medications or preventive measures for allergic rhinitis. ${ }^{1}$ Several consensus reports stress the importance of environmental control aiming at the reduction of exposure to house-dust mites among patients with allergic rhinitis. ${ }^{2,3}$ Surprisingly, there is little evidence that such interventions have a beneficial effect on the symptoms of rhinitis. In a recent Cochrane review, Sheikh and Hurwitz selected four trials that fulfilled the criteria for randomized clinical trials, all involving patients with allergic rhinitis. ${ }^{4}$ The studies that were included were considered to be small and of poor quality. Only one uncontrolled study had investigated the effects of bedroom-based allergen-avoidance measures, including the use of covers wrapping the mattress. ${ }^{5}$ On the basis of early reports of the effectiveness of these covers when used by patients with asthma, ${ }^{6-8}$ this intervention has been put forward in U.S. ${ }^{9}$ and European ${ }^{2,3,10}$ guidelines as the first and most effective allergy-control measure that can be taken by patients. The use of covers to encase bedding has been proposed as an essential action, whereas the removal of carpets and the minimization of the amount of upholstered furniture have been described as desirable actions. ${ }^{11}$

Environmental control, however, represents a financial burden for both patients and society. In the Netherlands, financial reimbursement for bedding covers can be obtained from health insurance companies. Yearly compensation was estimated at \$2.4 million in 2001 (Holwerda BMP, Dutch Health Insurance Board: personal communication). At the same rate of reimbursement, about $\$ 42$ million would be spent on such covers in the United States. A recent U.S. position paper urges insurers and other third-party payers to cover the costs of impermeable covers for mattresses, comforters, and pillows, as well as other proven therapies designed to reduce exposure to allergens. ${ }^{9}$ In the Netherlands, insurers already offer financial compensation for the purchase of bedding covers. The financial implication of such a policy or recommendation necessitates rigorous studies to assess the effectiveness of impermeable covers as a part of allergy-control measures in daily practice. We conducted a large multicenter trial to examine the clinical effects of mite-proof covers for the bedding of mite-sensitive patients on the symptoms and signs of allergic rhinitis.

\section{METHODS}

\section{STUDY SETTING AND PATIENTS}

The study was part of a larger trial involving patients with allergic rhinitis, asthma, atopic dermatitis, or some combination of these conditions (the Dutch Mite Avoidance Study). The setting and study design have been described elsewhere. ${ }^{12}$ Potentially eligible patients had to meet our definition of housedust-mite sensitization ${ }^{3}$; our use of patients from the larger study allowed us to select patients with allergic asthma or atopic dermatitis, provided that they also had a diagnosis of rhinitis. All study patients were required to have one or more symptoms; nasal obstruction was present in 86 percent of the patients, watery nasal discharge in 82 percent, sneezing in 94 percent, and nasal itching in 78 percent. Of the patients who were included, 95 percent had nasal symptoms arising from exposure to dust in the home. Other nasal diseases and nasal deformities were ruled out with the use of rhinoscopy.

Skin tests and measurement of specific IgE were used to establish sensitization to mite allergen. Since it may be difficult to diagnose perennial allergic rhinitis, we also required patients to have a positive nasal allergen-challenge test as an additional diagnostic criterion. With this test, we prove that nasal exposure to mite allergen elicits symptoms in a dose-dependent manner. ${ }^{13}$ Other criteria for inclusion and exclusion are shown in Table 1. Among the 325 eligible patients entering the Dutch Mite Avoidance Study, the group with rhinitis was by far the largest (279 patients). The study protocol was approved by the medical ethics committees of all three participating university hospitals, and all patients gave written informed consent.

\section{STUDY DESIGN AND BLINDING}

The study was designed as a randomized, doubleblind, placebo-controlled trial. At base line, eligible patients were randomly assigned to receive either covers for bedding that were not impermeable to mite allergen (control covers) or impermeable bedding covers; assignments were made at the Julius Center with the use of a central computerized randomization schedule. The control covers used in the study had an unloaded pore size of $0.1 \times 0.08 \mathrm{~mm}$; the application of a force of $200 \mathrm{~N}$ changed the pore size to $0.1 \times 0.1 \mathrm{~mm}$. The control covers provided a 15 percent barrier against allergen (allowing 85 percent of allergen to pass through), as compared with the 98 percent barrier provided by the imper- 
meable covers. After randomization, the patient's initials and date of birth and the measurements of his or her pillows, duvets, and mattress were faxed to the Julius Center. Each patient was assigned a research number. The research number and the bedding measurements were sent by the Julius Center to the manufacturer of the covers (Haarlem Allergen Laboratories). A cardboard box containing all covers was sent to the research center, with the research number written on the box. Each patient took his or her box home and opened it in the absence of research staff. Covers were put on pillows, duvets, and mattresses after base-line dust collection. Dust sampling was performed by trained students who did not participate in the obtaining of clinical measurements, in order to ensure blinding.

The use of covers was part of a protocol-driven allergy-control program in which participants were encouraged to wash and clean the bedding weekly in water that was $60^{\circ} \mathrm{C}$ and to clean, heat, and ventilate their homes according to a regular schedule, as outlined in the guidelines of the Netherlands Asthma Foundation (which, in turn, are based on international guidelines ${ }^{9,10}$ ). In addition, we urged patients not to replace duvets, blankets, or mattresses and not to change floor surfaces, upholstered furniture, or carpets after the start of the trial.

\section{CLINICAL MEASUREMENTS}

All clinical measurements at base line and after 12 months of treatment were obtained between September and December, the peak season for housedust mites in the Netherlands. Study patients with an allergy to pollen were seen in October or November, at least one month after the end of the pollen season. All antihistamine use was discontinued at least three days before clinical measurements and all nasal-spray use was discontinued two to four weeks before clinical measurements, so that the results of nasal allergen-provocation testing would not be influenced by treatments. Before the covers were put on the bedding, patients visited the research center on two consecutive days, when they filled in visual-analogue scales and quality-of-life questionnaires and underwent a nasal allergen-provocation test, skin tests, and lung-function tests (described below). For 14 days before these base-line visits, patients recorded a daily symptom score (described below). The patients put the covers on their bedding in their bedrooms after dust samples had been collected. For each patient, the presence or absence of coexisting allergic asthma and atopic dermatitis was assessed according to preset criteria. ${ }^{12}$
Table 1. Criteria for Inclusion and Exclusion."

\section{Criteria for Inclusion}

An age of 8-50 yr

Patient not pregnant or lactating

No bedding covers in place or patient willing to remove them for the duration of the study

Clinical history of allergic rhinitis and a positive nasal allergen-provocation test with house-dust-mite allergen

RAST class $\geq 2$, skin-test index $\geq 0.7$ for house-dust mite, or both

$\geq 0.2 \mu$ g of Der $\mathrm{pl}$ or Der $\mathrm{fl}$ per gram of dust in sample from mattress

\section{Criteria for Exclusion} (index $\geq 0.7$ ), RAST class $\geq 2$, or both for the pet allergen

Daily use of inhaled corticosteroids $\geq 1600 \mu \mathrm{g} /$ day (in adults) or $\geq 800 \mu \mathrm{g} /$ day (in children)

Daily use of oral corticosteroids

Daily use of cyclosporine

Regular use of antibiotics for upper or lower airway infection

Regular use of oral corticosteroids for exacerbations of asthma
Pets at home and a positive skin test

* Radioallergosorbent test (RAST) class 2 is defined by an anti-house-dust-mite IgE level of 0.7 to $3.5 \mathrm{kU}$ per liter. The skin-test index is the quotient of the diameter of the allergen-induced wheal divided by the diameter of the histamine-induced wheal, determined according to a validated protocol. ${ }^{14,15}$

\section{PRIMARY END POINT}

The primary end point was the score on the rhinitis-specific visual-analogue scale, which measures the severity of the disease as experienced by the patient. Scores range from 0 (no symptoms) to 100 (very severe symptoms). In previous studies, visualanalogue scales have been demonstrated to be sensitive and reliable outcome measures. ${ }^{16-19}$

\section{SECONDARY END POINTS}

Secondary end points included the daily symptom score, the score on nasal allergen-provocation testing, and concentrations of Dermatophagoides pteronyssinus (Der p1) and D. farinae (Der f1) in dust samples from the patient's mattress, bedroom floor, and living-room floor. For the daily symptom score, patients recorded symptoms on a daily symptom card for 14 consecutive days before their first screening. In this symptom diary, they noted occurrences of nasal obstruction, nasal discharge, and nasal itching. The severity of symptoms was scored on a four-point scale (with a score of 0 denoting no symptoms at all and a score of 3 denoting very serious symptoms). The average score for an item was calculated if a score for that item was recorded on at least 12 of the 14 days. The daily symptom score, which has been proved to reflect the response to treatment in many randomized clinical trials, ${ }^{17,20,21}$ was calculated as the average of the mean scores for the three items.

Nasal allergen-provocation tests were included for purposes of diagnosis, and the score on these tests was included as a secondary end point. ${ }^{22}$ As previously described, ${ }^{23}$ the response to nasal chal- 
lenge with house-dust-mite extract in doses of 100 , 1000 , and 10,000 biologic units per milliliter was assessed with the use of a symptom score with a range of 0 to 12 points, with a maximum of 36 points. ${ }^{24}$

The vacuuming procedures for the collection, extraction, and analysis of dust samples at base line and after 12 months have been described extensively elsewhere. ${ }^{25}$ Mattress dust was collected with the bottom sheet still on the mattress. In addition, dust samples were obtained from the bedroom and living-room floors. The concentration of Der $\mathrm{p} 1$ was measured relative to the World Health Organization reference values by competitive radioimmunoassay ${ }^{26}$; the results in nanograms per international unit (IU) were converted to micrograms per gram of dust with the use of 0.125 as the conversion factor. The concentration of Der f1 was measured by monoclonal enzyme-linked immunosorbent assay (Indoor Biotechnologies).

\section{STATISTICAL ANALYSIS}

Before the conduct of the study, we estimated that we needed at least 44 patients in each group, on the assumption that a clinically relevant reduction of 25 percent from a mean $( \pm S D)$ score on the visualanalogue scale of $54 \pm 27$ points $^{27}$ could be detected with a power of 90 percent and a two-tailed alpha level of 0.05 .

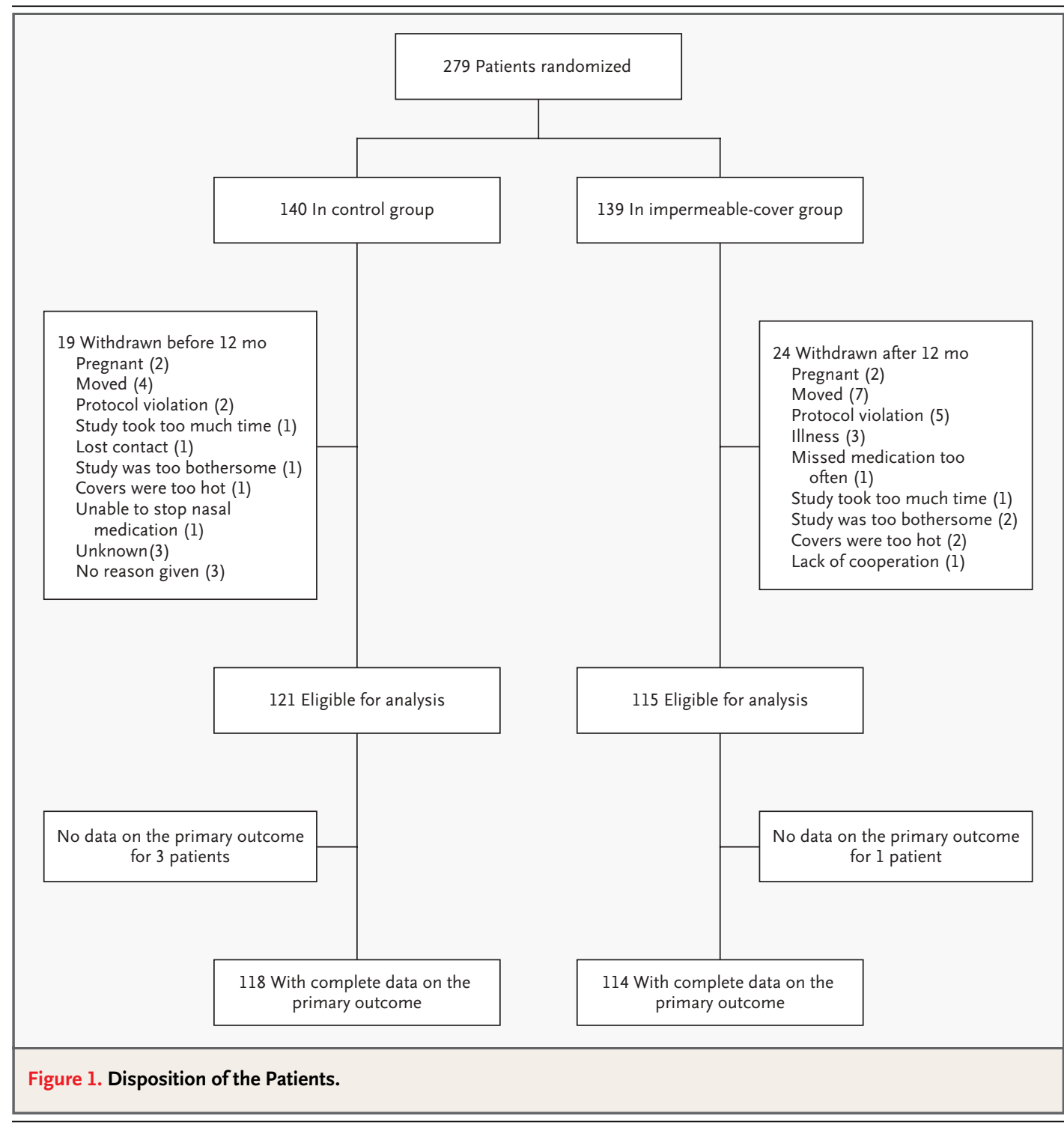


Log transformation was performed for the sum of the Der p1 and Der f1 concentrations, the total and specific IgE concentrations, and the eosinophil count. Intention-to-treat analysis was performed with the use of data on all 232 patients from whom valid scores on the visual-analogue scale could be obtained after 12 months. Effectiveness was estimated with the use of unpaired t-tests to assess the mean difference between groups (or the mean ratio, for log-transformed variables) in changes from base line in the scores on the visual-analogue scale and in the secondary end points and their corresponding 95 percent confidence intervals.

In subgroup analyses, we examined potential effect modification with regard to scores on the visual-analogue scale by sensitization to other allergens (weed pollen, cat allergen, or dog allergen), characteristics of the inside of the patient's home (smooth surfaces vs. other types of surfaces), degree of sensitivity to house-dust-mite allergen (a radioallergosorbent test [RAST] class of 4, 5, or 6 vs. a RAST class of less than 4, representing anti-house-dustmite IgE levels above $17.5 \mathrm{kU}$ per liter and levels of $17.5 \mathrm{kU}$ per liter or below, respectively) and the concentration of Der p1 and Der f1 ( $\geq 5 \mu \mathrm{g} v \mathrm{vs} .<5 \mu \mathrm{g}$ of Der $\mathrm{p} 1$ and Der f1 per gram of dust).

\section{RESULTS}

After 12 months, the geometric mean concentration of Der p1 and Der f1 in the mattress samples was significantly lower in the impermeable-cover group. The ratio of the level 12 months after the covers were put on to the level before the covers were put on was 0.31 in the impermeable-cover group (95 percent confidence interval, 0.21 to 0.46 ), as compared with a ratio of 0.82 in the control group (95 percent confidence interval, 0.58 to 1.15 ). The reductions from base line to 12 months in the concentration of Der p1 and Der f1 in bedroom-floor dust were not statistically significant in the control group (mean ratio of the level at 12 months to the level at the beginning of the study, $0.83 ; \mathrm{P}=0.49$ ), whereas there was a statistically significant reduction in the group using impermeable covers (mean ratio, $0.69 ; \mathrm{P}=0.04$ ). However, the intervention was not found to have a significant effect ( $\mathrm{P}=0.44$ by unpaired $t$-test). A somewhat larger, statistically significant reduction was found for the concentration in livingroom-floor dust in the control group (mean ratio of the 12-month level to the beginning level, 0.67; $\mathrm{P}=0.01$ by paired $t$-test, as compared with a ratio of

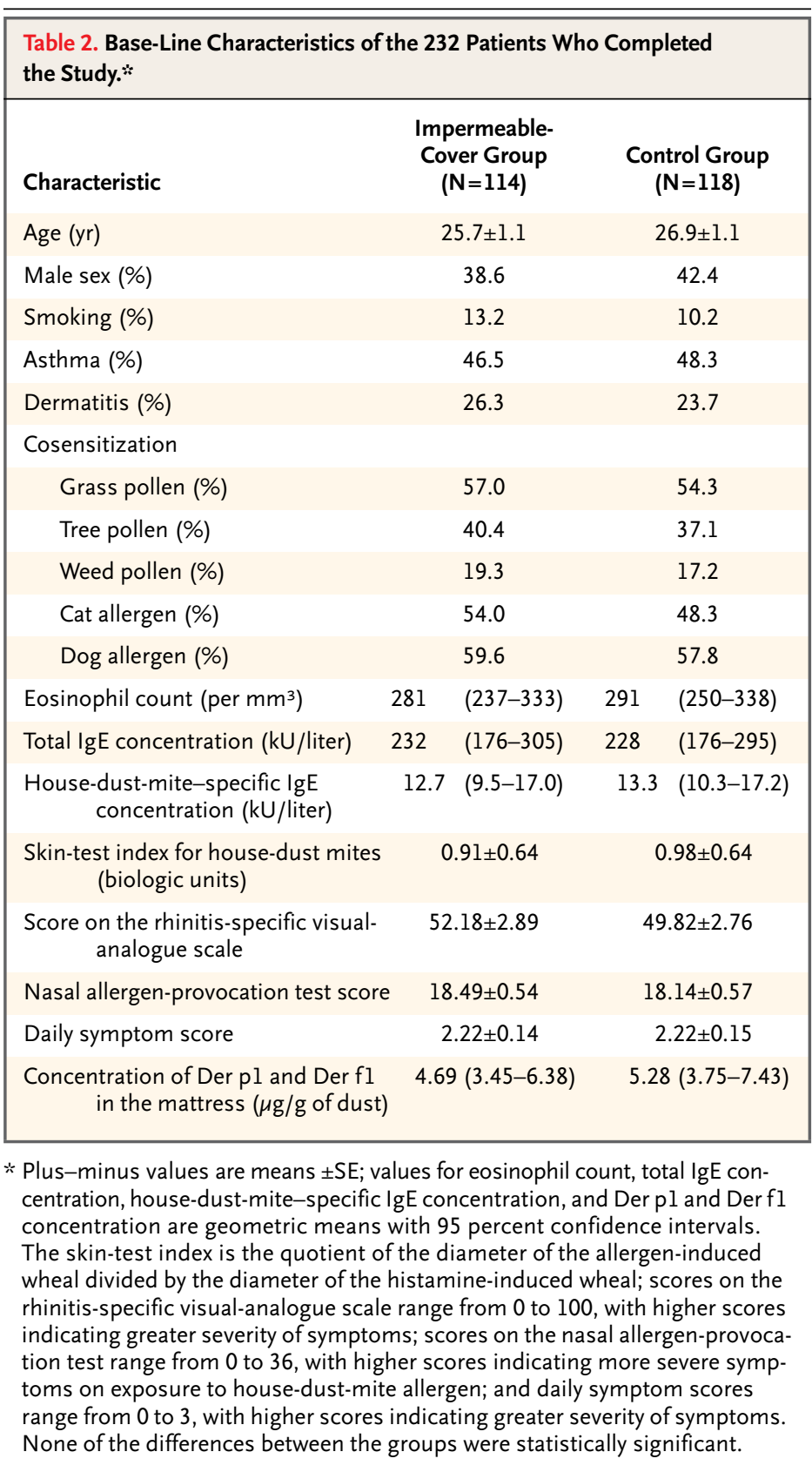

$0.90[\mathrm{P}=0.49]$ in the impermeable-cover group). Again, the intervention was not found to have a significant effect $(\mathrm{P}=0.21$ by unpaired $\mathrm{t}$-test).

The disposition of patients in the trial is shown in Figure 1. The base-line clinical characteristics were similar in the control group and the impermeable-cover group (Table 2). Patients in both groups had a significant decrease in the mean score on the visual-analogue scale $(\mathrm{P}<0.001$ for both changes). A small decrease in the daily symptom 


\begin{tabular}{|c|c|c|c|}
\hline Variable & Impermeable-Cover Group & Control Group & P Value \\
\hline \multicolumn{4}{|l|}{ Primary end point } \\
\hline \multicolumn{4}{|l|}{ Rhinitis-specific visual-analogue scale } \\
\hline No. of patients & 114 & 118 & \\
\hline Base-line score & $52.18 \pm 2.89$ & $49.82 \pm 2.76$ & 0.56 \\
\hline 12-Mo score & $42.35 \pm 2.79$ & $38.96 \pm 2.68$ & 0.38 \\
\hline Mean change $(95 \% \mathrm{Cl})$ & $-9.83(-15.28$ to -4.39$)$ & $-10.86(-16.64$ to -5.09$)$ & \\
\hline Pvalue & $<0.001$ & $<0.001$ & \\
\hline Difference between changes $(95 \% \mathrm{Cl})$ & \multicolumn{2}{|c|}{$1.03(-6.87$ to 8.94$)$} & 0.80 \\
\hline \multicolumn{4}{|l|}{ Secondary end points } \\
\hline \multicolumn{4}{|l|}{ Nasal allergen-provocation test } \\
\hline No. of patients & 112 & 114 & \\
\hline Base-line score & $18.49 \pm 0.55$ & $17.92 \pm 0.57$ & 0.47 \\
\hline 12-Mo score & $18.26 \pm 0.60$ & $17.59 \pm 0.60$ & 0.43 \\
\hline Mean change $(95 \% \mathrm{Cl})$ & $-0.23(-1.28$ to 0.81$)$ & $-0.33(-1.42$ to 0.76$)$ & \\
\hline Pvalue & 0.66 & 0.55 & \\
\hline Difference between changes $(95 \% \mathrm{Cl})$ & \multicolumn{2}{|c|}{$0.10(-1.40$ to 1.60$)$} & 0.90 \\
\hline \multicolumn{4}{|l|}{ Daily symptom score } \\
\hline No. of patients & 100 & 98 & \\
\hline Base-line score & $2.25 \pm 0.15$ & $2.23 \pm 0.16$ & 0.93 \\
\hline 12-Mo score & $2.07 \pm 0.16$ & $1.91 \pm 0.17$ & 0.47 \\
\hline Mean change $(95 \% \mathrm{Cl})$ & $-0.18(-0.45$ to 0.1$)$ & $-0.33(-0.63$ to -0.02$)$ & \\
\hline$P$ value & 0.20 & 0.04 & \\
\hline Difference between changes $(95 \% \mathrm{Cl})$ & \multicolumn{2}{|c|}{$0.15(-0.26$ to 0.56$)$} & 0.48 \\
\hline \multicolumn{4}{|l|}{ Der $\mathrm{pl}$ and Der $\mathrm{fl}$ in mattress ( $\mu \mathrm{g} / \mathrm{g}$ of dust) } \\
\hline No. of patients & 79 & 87 & \\
\hline Base-line concentration $\uparrow$ & $4.12(2.93-5.79)$ & $5.91(4.00-8.73)$ & 0.18 \\
\hline 12-Mo concentration $†$ & $1.29(0.95-1.75)$ & $4.84(3.62-6.47)$ & $<0.001$ \\
\hline Mean change $(95 \% \mathrm{Cl}) ‡$ & 0.31 (0.21 to 0.46$)$ & 0.82 (0.58 to 1.15$)$ & \\
\hline Pvalue & $<0.001$ & 0.25 & \\
\hline Difference between changes $(95 \% \mathrm{Cl}) \mathbb{\int}$ & \multicolumn{2}{|c|}{0.38 (0.23 to 0.64$)$} & $<0.001$ \\
\hline \multicolumn{4}{|c|}{$\begin{array}{l}\text { * Plus-minus values are means } \pm \text { SE unless otherwise indicated. Scores on the rhinitis-specific visual-analogue scale range } \\
\text { from } 0 \text { to } 100 \text {, with higher scores indicating greater severity of symptoms; scores on the nasal allergen-provocation test } \\
\text { range from } 0 \text { to } 36 \text {, with higher scores indicating more severe symptoms on exposure to house-dust-mite allergen; and } \\
\text { daily symptom scores range from } 0 \text { to } 3 \text {, with higher scores indicating greater severity of symptoms. Cl denotes confi- } \\
\text { dence interval. } \\
T \text { Values are geometric means with } 95 \text { percent confidence inervals. } \\
\text { Data are the ratios of the concentration at } 12 \text { months to the concentration at base line. } \\
\text { I Value is the ratio of the mean change in the impermeable-cover group to the mean change in the control group. }\end{array}$} \\
\hline
\end{tabular}


score was seen in the control group. However, there was no significant difference between groups in the score on the visual-analogue scale, the nasal allergen-provocation score, or the daily symptom score (Table 3). A subgroup of 74 patients (31.9 percent) were not sensitized to weed pollen, cat allergen, or dog allergen, whereas 100 patients (43.1 percent) had smooth floor surfaces in their bedroom and living room and no rugs in the bedroom.

On multivariate regression analysis, including the intervention as the main determinant, as well as age, smoking status, sex, cosensitization to other allergens, characteristics of the interior of the patient's home, and terms for the interactions between these factors and the intervention, we found no statistically significant modification of the effect of the intervention by any of these characteristics. Subgroup analyses showed that sensitization to house-dust-mite allergen alone or to multiple allergens, characteristics of the interior of the patient's home, and the level of exposure to Der $\mathrm{p} 1$ and Der f1 did not influence the effect of the intervention on the primary outcome measure (Table 4). We did not find greater improvement in the scores on the visual-analogue scale in the impermeable-cover group than in the control group, either among 157 patients with high sensitivity to dust-mite allergen (mean in the impermeable-cover group minus the mean in the control group, 1.32 [95 percent confidence interval, -8.70 to 11.35$] ; \mathrm{P}=0.79$ ) or among 75 patients with low sensitivity to dust-mite allergen (mean in the impermeable-cover group minus the mean in the control group, -5.40 [95 percent confidence interval, -18.22 to 7.43 ]; $\mathrm{P}=0.40$ ).

\section{DISCUSSION}

Our randomized, controlled trial involving patients with allergic rhinitis demonstrated a lack of clinical effect of mite-proof covers for mattresses, pillows, and duvets on signs and symptoms of rhinitis. No clinical effect was seen despite a significant reduction (by a factor of 2.6) in the level of exposure to house-dust mites in the mattress. A similar lack of effect of mattress encasings in the much smaller subgroups of patients from the Dutch Mite Avoidance Study who had atopic dermatitis ${ }^{25}$ or asthma were in line with our overall results. Furthermore, our findings are in accordance with a recently updated meta-analysis of 29 trials involving 939 patients with asthma showing that physical methods (in 15 trials), chemical methods (in 9 trials), or a combination of methods (in 5 trials) did not result in the improvement of symptoms of asthma. ${ }^{28}$

There are limitations to this study. Although 279 patients were included in the study, we were able to examine only 232 patients at the end of the study. The dropout rate did not appear to vary according to the presence or absence of known risk factors. Adjustment for known differences between the two groups did not change the direction or magnitude of the results. Furthermore, the study population was heterogeneous - that is, patients were recruited from tertiary referral departments, general hospitals, and general practices and by advertisements. Moreover, patients with asthma or atopic dermatitis were also eligible for inclusion in the Dutch Mite Avoidance Study, ${ }^{25}$ so the prevalence of these coexisting conditions and the mean IgE values were high among the study patients. The advantage of the recruitment process is that the study population is representative of all patients with rhinitis seen in clinical practice for whom bedding covers are recommended by consensus statements. The disadvantage is that very selected groups of patients who might benefit from the intervention could not be identified. However, in the subgroups that could be analyzed, we were not able to identify such a group of patients.

Possibly, the base-line level of Der p1 and Der f1 was too low, and consequently, the reduction in allergen exposure could only be moderate. Other studies have demonstrated much larger reductions in the concentration of Der p1.29,30 The base-line levels we observed, however, were in line with the results of the large-scale Dutch Prevention and Incidence of Asthma and Mite Allergy study that involved 810 very young children. ${ }^{31}$ Apparently, either patients who were sensitized to house-dust mites had already applied some measures to lower housedust-mite levels before entering the trial or the living conditions were unfavorable to the growth of housedust mites. Subgroup analysis of patients with a high level of exposure did not reveal any clinical effect from impermeable covers. Therefore, the level of exposure seems not to be a major constraint in our study.

Our results do not preclude possible effectiveness of environmental control measures in general. Our objective was to establish the specific and isolated effect of covers for mattresses, duvets, and pillows in patients with allergic rhinitis who are allergic to house-dust-mite allergen. Other sources of house-dust-mite allergen are the bedroom and liv- 


\begin{tabular}{|c|c|c|c|}
\hline Variable & Impermeable-Cover Group & Control Group & $P$ Value \\
\hline \multicolumn{4}{|l|}{ Patients not sensitized to other allergens } \\
\hline No. of patients & 35 & 39 & \\
\hline Base-line score & $54.86 \pm 5.09$ & $47.33 \pm 4.56$ & 0.27 \\
\hline 12-Mo score & $43.91 \pm 5.15$ & $38.33 \pm 4.58$ & 0.42 \\
\hline Mean change $(95 \% \mathrm{Cl})$ & $-10.94(-19.38$ to -2.50$)$ & $-9.00(-19.68$ to 1.68$)$ & \\
\hline$P$ value & 0.13 & 0.10 & \\
\hline Difference between changes $(95 \% \mathrm{Cl})$ & \multicolumn{2}{|c|}{$-1.94(-15.54$ to 11.65$)$} & 0.29 \\
\hline \multicolumn{4}{|l|}{ Patients sensitized to other allergens } \\
\hline No. of patients & 79 & 79 & \\
\hline Base-line score & $51.00 \pm 3.52$ & $51.05 \pm 3.47$ & 0.99 \\
\hline 12-Mo score & $41.66 \pm 3.33$ & $39.27 \pm 3.32$ & 0.80 \\
\hline Mean change $(95 \% \mathrm{Cl})$ & $-9.34(-16.37$ to -2.32$)$ & $-11.78(-18.77$ to -4.80$)$ & \\
\hline P value & 0.01 & 0.001 & \\
\hline Difference between changes $(95 \% \mathrm{Cl})$ & \multicolumn{2}{|c|}{$2.44(-7.39$ to 12.27$)$} & 0.77 \\
\hline \multicolumn{4}{|l|}{$\begin{array}{c}\text { Patients with wall-to-wall carpets or rugs in } \\
\text { bedroom, living room, or both }\end{array}$} \\
\hline No. of patients & 64 & 68 & \\
\hline Base-line score & $53.88 \pm 3.70$ & $51.59 \pm 3.69$ & 0.66 \\
\hline 12-Mo score & $41.91 \pm 3.67$ & $41.41 \pm 3.82$ & 0.93 \\
\hline Mean change $(95 \% \mathrm{Cl})$ & $-11.97(-19.39$ to -4.55$)$ & $-10.18(-17.00$ to -3.35$)$ & \\
\hline P value & 0.002 & 0.004 & \\
\hline Difference between changes $(95 \% \mathrm{Cl})$ & \multicolumn{2}{|c|}{$-1.79(-11.76$ to 8.19$)$} & 0.72 \\
\hline \multicolumn{4}{|c|}{$\begin{array}{l}\text { Patients with smooth floor surfaces and no rugs } \\
\text { in the bedroom }\end{array}$} \\
\hline No. of patients & 50 & 50 & \\
\hline Base-line score & $50.02 \pm 4.60$ & $47.42 \pm 4.20$ & 0.68 \\
\hline 12-Mo score & $42.92 \pm 4.31$ & $35.60 \pm 3.59$ & 0.20 \\
\hline Mean change $(95 \% \mathrm{Cl})$ & $-7.10(-15.33$ to 1.13$)$ & $-11.80(-22.06$ to 1.54$)$ & \\
\hline$P$ value & 0.09 & 0.02 & \\
\hline Difference between changes $(95 \% \mathrm{Cl})$ & \multicolumn{2}{|c|}{$4.70(-8.30$ to 17.70$)$} & 0.48 \\
\hline
\end{tabular}

ing-room floors ${ }^{32}$ and clothing. ${ }^{33}$ Since reductions from base line in the concentration of Der p1 and Der $\mathrm{f} 1$ in samples from the bedroom and livingroom floors were either small or absent, the use of covers cannot control allergen from these sources. With respect to other allergens, allergy to mold is uncommon in the Netherlands, ${ }^{34}$ and cockroach infestation was not observed during the visits to patients' homes. Moreover, in the Netherlands, no data are available suggesting that cockroach allergen is an important cause of allergy. Sensitization to other allergens that were not controlled for in this study may have masked potential benefits from covers, but data from the subgroup analysis do not sup- 


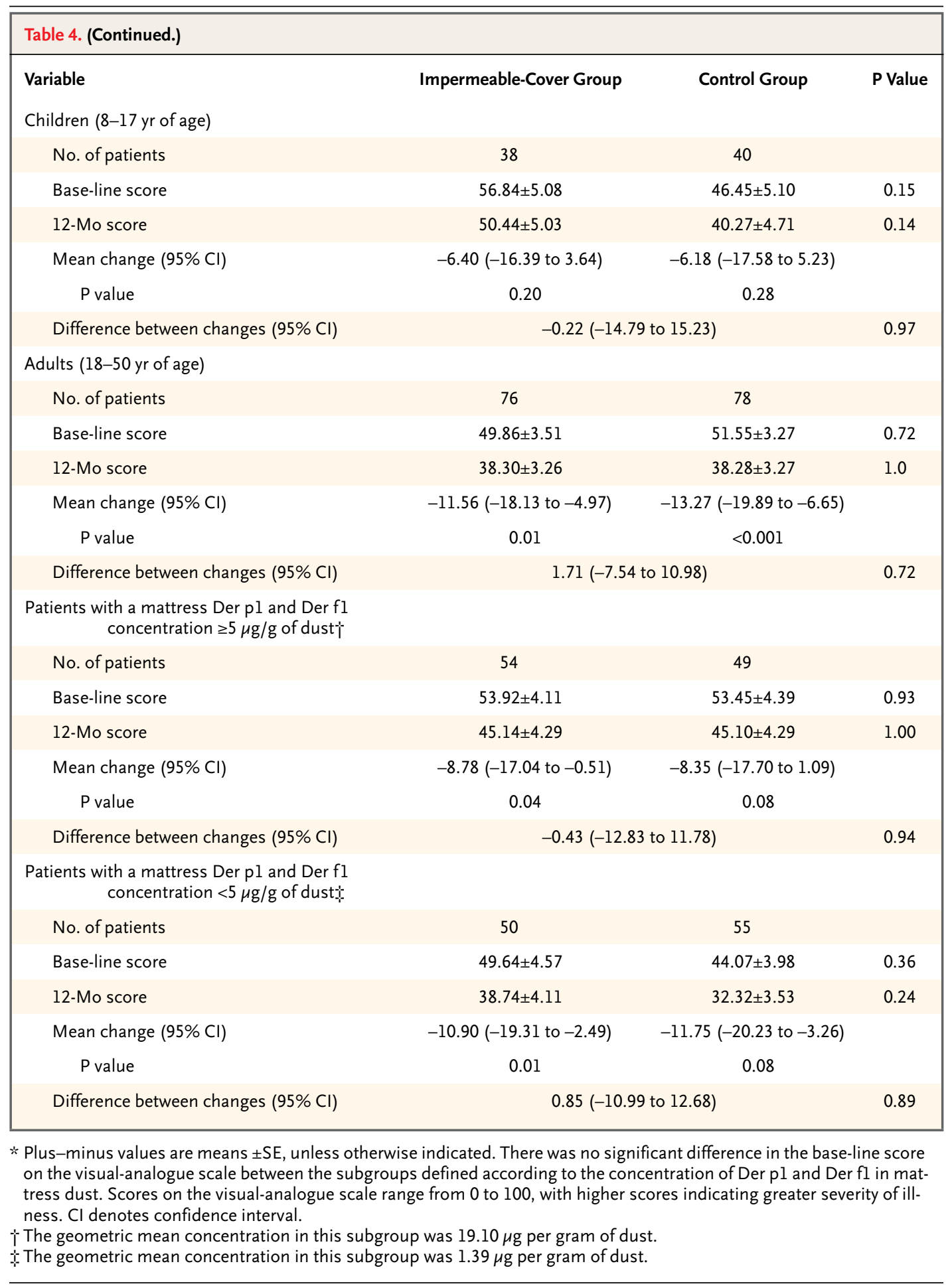

port this possibility. In conclusion, our study does house-dust-mite allergen, in spite of a significant not lend support to a possible benefit of covers in reduction in house-dust-mite exposure.

the bedroom as part of measures for allergy control Supported by the Netherlands Organization for Health Research in patients with allergic rhinitis who are allergic to and Development. 
We are indebted to J.H. Broeshart, M.D., S.H. Hendriks, M.D., Haarlem Allergen Laboratories (Haarlem, the Netherlands) for proA.J. van Oorschot-van Nes, L. Havekes, D. van der Naald, and B. viding the covers.

Verkerk for their invaluable contributions to the project; and to

REFERENCES

1. Weiss KB, Sullivan SD. The health economics of asthma and rhinitis. I. Assessing the economic impact. J Allergy Clin Immunol 2001;107:3-8.

2. van Cauwenberge $\mathrm{P}$, Bachert $\mathrm{C}$, Passalacqua $\mathrm{G}$, et al. Consensus statement on the treatment of allergic rhinitis. Allergy 2000; 55:116-34.

3. International Rhinitis Management Working Group. International Consensus Report on the diagnosis and management of rhinitis. Allergy 1994;49:Suppl:1-34.

4. Sheikh A, Hurwitz B. House dust mite avoidance measures for perennial allergic rhinitis. Cochrane Database Syst Rev 2001 4:CD001563.

5. Moon JS, Choi SO. Environmental controls in reducing house dust mites and nasa symptoms in patients with allergic rhinitis. Yonsei Med J 1999;40:238-43.

6. Frederick JM, Warner JO, Jessop WJ, Enander I, Warner JA. Effect of a bed covering system in children with asthma and house dust mite hypersensitivity. Eur Respir J 1997;10:361-6.

7. Ehnert B, Lau-Schadendorf S, Weber A Buettner P, Schou C, Wahn U. Reducing domestic exposure to dust mite allergen reduces bronchial hyperreactivity in sensitive children with asthma. J Allergy Clin Immuno 1992; $90: 135-8$

8. van der Heide S, Kauffman HF, Dubois AE, de MonchyJG. Allergen-avoidance meas ures in homes of house-dust-mite-allergic asthmatic patients: effects of acaricides and mattress encasings. Allergy 1997;52:921-7.

9. Ad Hoc Working Group on Environmental Allergens and Asthma. Environmental allergen avoidance in allergic asthma. J Allergy Clin Immunol 1999;103:203-5. 10. Bousquet J, Van Cauwenberge P, Khaltaev N. Allergic rhinitis and its impact on asthma. J Allergy Clin Immunol 2001;108 Suppl:S147-S334

11. Allergy report, 2000. Milwaukee: American Academy of Allergy, Asthma \& Immunology, 2001. (Accessed June 23, 2003, at http:/ www.theallergyreport.org/reportindex.html.) 12. Terreehorst I, Oosting AJ, Tempels-Pavlica Z, et al. Prevalence and severity of allergic rhinitis in house dust mite-allergic patients with bronchial asthma or atopic dermatitis. Clin Exp Allergy 2002;32:1160-5.

13. Malm L, Gerth van Wijk R, Bachert C. Guidelines for nasal provocations with aspects on nasal patency, airflow, and airflow resistance. Rhinology 2000;38:1-6. 14. Niemeijer NR, Fluks AF, de Monchy JG.
Optimization of skin testing. II. Evaluation of concentration and cutoff values, as compared with RAST and clinical history, in a multicenter study. Allergy 1993;48:498-503. 15. Niemeijer NR, Goedewaagen B, Kauffman HF, de MonchyJG. Optimization of skin testing. I. Choosing allergen concentrations and cutoff values by factorial design. Allergy 1993;48:491-7.

16. Blom HM, Van RijswijkJB, Garrelds IM, Mulder PG, Timmermans T, Gerth van Wijk $\mathrm{R}$. Intranasal capsaicin is efficacious in nonallergic, non-infectious perennial rhinitis a placebo-controlled study. Clin Exp Allergy 1997;27:796-801.

17. Varney VA, Gaga M, Frew AJ, Aber VR, Kay AB, Durham SR. Usefulness of immunotherapy in patients with severe summer hay fever uncontrolled by antiallergic drugs. BMJ 1991;302:265-9.

8. Herman D, Garay R, Le Gal M. A randomized double-blind placebo controlled study of azelastine nasal spray in children with perennial rhinitis. Int J Pediatr Otorhinolaryngol 1997;39:1-8

19. Koepke JW, Beaucher WN, Kobayash $\mathrm{RH}$, et al. Long-term safety and efficacy of triamcinolone acetonide aqueous nasal spray for the treatment of perennial allergic rhinitis. Allergy Asthma Proc 1997;18:33-7. [Erratum, Allergy Asthma Proc 1999;20:337.]

20. Durham SR, Walker SM, Varga E-M, et al. Long-term clinical efficacy of grass-pollen immunotherapy. N Engl J Med 1999;341: 468-75.

21. Casale TB, Condemi J, LaForce C, et al. Effect of omalizumab on symptoms of seasonal allergic rhinitis: a randomized controlled trial. JAMA 2001;286:2956-67.

22. de Graaf-in't Veld C, Garrelds IM, van Toorenenbergen AW, Gerth van Wijk R. Nasal responsiveness to allergen and histamine in patients with perennial rhinitis with and without a late phase response. Thorax 1997 52:143-8.

23. de Graaf-in 't Veld T, Garrelds IM, van Toorenenbergen AW, Mulder PG, Gerth van Wijk R, Boegheim JP. Effect of topical levocabastine on nasal response to allergen challenge and nasal hyperreactivity in perennial rhinitis. Ann Allergy Asthma Immunol 1995 75:261-6

24. Lebel B, Bousquet J, Morel A, Chanal I, Godard P, Michel FB. Correlation between symptoms and the threshold for release of mediators in nasal secretions during nasal challenge with grass-pollen grains. J Allergy Clin Immunol 1988;82:869-77.
25. Oosting AJ, de Bruin-Weller MS, Terreehorst I, et al. Effect of mattress encasings on atopic dermatitis outcome measures in a double-blind, placebo-controlled study: the Dutch Mite Avoidance Study. J Allergy Clin Immunol 2002;110:500-6.

26. van Ree $R$, van Leeuwen WA, van den Berg M, Weller HH, Aalberse RC. IgE and IgG cross-reactivity among Lol p I and Lol p II/ III: identification of the C-termini of Lol p I, II, and III as cross-reactive structures. Allergy 1994;49:254-61.

27. Gerth Van Wijk R, Terreehorst IT, Mulder PG, Garrelds IM, Blom HM, Popering S. Intranasal capsaicin is lacking therapeutic effect in perennial allergic rhinitis to house dust mite: a placebo-controlled study. Clin Exp Allergy 2000;30:1792-8.

28. Gøtzsche PC, Johansen HK, Burr ML, Hammerquist C. House dust mite control measures for asthma. Cochrane Database Syst Rev 2001;3:CD001187.

29. Cloosterman SG, Schermer TR, BijlHofland ID, et al. Effects of house dust mite avoidance measures on Der $\mathrm{p} 1$ concentrations and clinical condition of mild adult house dust mite-allergic asthmatic patients, using no inhaled steroids. Clin Exp Allergy 1999;29:1336-46

30. Vanlaar CH, Peat JK, Marks GB, Rimmer J, Tovey ER. Domestic control of house dust mite allergen in children's beds. J Allergy Clin Immunol 2000;105:1130-3.

31. van Strien RT, Koopman LP, Kerkhof M, et al. Mite and pet allergen levels in homes of children born to allergic and nonallergic parents: the PIAMA study. Environ Health Perspect 2002;110:A693-A698.

32. Marks GB, Tovey ER, Toelle BG, Wachinger S, Peat JK, Woolcock AJ. Mite allergen (Der p 1) concentration in houses and its relation to the presence and severity of asthma in a population of Sydney schoolchildren. J Allergy Clin Immunol 1995;96:441-8.

33. De Lucca SD, O'Meara TJ, Tovey ER. Exposure to mite and cat allergens on a range of clothing items at home and the transfer of cat allergen in the workplace. J Allergy Clin Immunol 2000;106:874-9.

34. Beaumont F, Kauffman HF, de Monchy JG, Sluiter HJ, de Vries K. Volumetric aerobiological survey of conidial fungi in the North-East Netherlands. II. Comparison of aerobiological data and skin tests with mould extracts in an asthmatic population. Allergy 1985;40:181-6.

Copyright (c) 2003 Massachusetts Medical Society. 